\title{
ENTRE O LAZER ESPORTIVO PARTICIPATIVO E AMBIENTAL E O LAZER TURÍSTICO - AS POLÍTICAS PÚBLICAS DE LAZER EM BROTAS/SP
}

\author{
BETWEEN PARTICIPATORY SPORTS AND ENVIRONMENTAL LEISURE AND \\ TOURISM LEISURE - LEISURE PUBLIC POLICIES IN BROTAS/SP
}

ENTRE EL OCIO DEPORTIVO PARTICIPATIVO Y AMBIENTAL Y OCIO

TURÍSTICO - LAS POLIITICAS PÚBLICAS DE OCIO EN BROTAS/SP

Olívia Cristina Ferreira Ribeiro*, Sílvia Cristina Franco Amaral*

\begin{abstract}
Palavras-chave Atividades de lazer. Desenvolvimento da comunidade. Políticas públicas. Ação intersetorial.

Resumo: 0 objetivo foi analisar a Lei Orgânica e o Plano Diretor que sustentam as políticas públicas de lazer de Brotas/SP. O enfoque foi dado aos pontos implementados, com especial atenção à gestão da intersetorial do lazer, uma das diretrizes de trabalho do município. O corpus documental foi composto por decretos, atas e despachos, complementado pela observação do cotidiano das ações de lazer do município. As legislações para o lazer em Brotas indicavam um equilíbrio entre o lazer esportivo participativo e ambiental e o lazer turístico, sendo que o segundo deveria gerar recursos e formação de pessoal para implementar políticas públicas voltadas ao cidadão brotense. Contudo, ao analisarmos as ações, identificamos um descompasso entre as duas ênfases dadas ao lazer. O lazer turístico de negócios foi o maior foco da prefeitura e houve nessa administração a facilitação do turismo exploratório, em que os negócios se direcionavam aos interesses privados e privatistas.
\end{abstract}

Keywords Leisure activities. Community development. Public policies. Intersector action.

Palabras clave Actividades de ocio. Desarrollo de la comunidad. Políticas Públicas. Acción intersectorial.

\begin{abstract}
The work analyzed the Organic Law and the Master Plan that underpin leisure policies in Brotas, SP, Brazil. The focus was on measures implemented, with special attention to management of the inter-sector coordination of leisure, one of the municipal guidelines. The document corpus included decrees, acts and ordinances, complemented by observation of daily leisure activities in that municipality. Brotas's leisure legislation indicated balance between participatory and environmental sports leisure and tourist leisure. The latter should generate resources and staff training for the former, in order to implement policies aimed at local citizens. However, by analyzing the actions, we found a mismatch between the two emphases given to leisure. Business tourism leisure was the focus of the municipal administration, which facilitated exploratory tourism where business aimed at private and privatizing interests.
\end{abstract}

Resumen: El objetivo fue analizar la Ley Orgánica y el Plan Director que sustentan las políticas públicas de ocio de Brotas/SP. El foco se colocó en los puntos implementados, con especial atención a la gestión intersectorial del ocio, una de las directrices de trabajo del municipio. El corpus documental fue compuesto por decretos, actas y despachos, complementados por la observación de la cotidianidad de las actividades de ocio del municipio. La legislación para el ocio en Brotas indicaba un equilibrio entre el ocio deportivo participativo y ambiental y el ocio turístico, donde el segundo debería generar recursos y capacitación del personal para implementar políticas públicas dirigidas a los ciudadanos de Brotas. Sin embargo, al analizar las acciones identificaron una falta de correspondencia entre los dos énfasis dados al ocio. El ocio turístico de negocios fue el foco principal del ayuntamiento y en esa administración se facilitó el turismo exploratorio, donde los negocios se dirigían a intereses privados y privatistas.
*Universidade de Campinas (Unicamp). Campinas, SP, Brasil.

E-mail: olivia@fef.unicamp.br

Recebido em: 10-12-2014 Aprovado em: 19-11-2015 (c) (i) () Licence 


\section{INTRODUÇÃO}

O artigo analisou as políticas públicas de lazer no tocante à intersetorialidade no município de Brotas, São Paulo, já que esse município tinha em seu discurso tal concepção de gestão. 0 recorte temporal de análise é de 2009-20121. Pequeno município do interior paulista, Brotas é conhecida em todo país pelas belezas naturais e pela diversidade de práticas corporais de lazer na natureza (rafting, boiacross, entre outras), que nas últimas décadas se transformaram no principal atrativo turístico da cidade.

A atividade turística se iniciou no final da década de 1980, mas foi nos anos 1990 que as práticas de lazer na natureza começaram a se destacar na cidade. Na década de 2000, foram criadas legislações específicas que contemplaram diferentes áreas do lazer. Inovadoras no país, serviram de modelo para outros municípios que tendiam a configurar inovações na gestão dessas políticas, dentre as quais a adoção da intersetorialidade. Motivadas por essa constatação, decidimos realizar a pesquisa sobre o tema. Este texto é parte de um trabalho mais amplo. Aqui analisamos as legislações concernentes às políticas públicas de lazer de Brotas/SP, em diálogo com a gestão do lazer nas áreas em que este se apresenta.

\section{METODOLOGIA}

Esta pesquisa de caráter descritivo-analítico utilizou a análise documental como principal método (MINAYO; DESLANDES; GOMES, 2009). Estudamos as legislações de Brotas, no que se refere ao lazer, especialmente nas Secretarias de Esporte, Cultura e Recreação e na de Turismo. Documentos oficiais, como programas, decretos, atas, entre outros, foram consultados.

Observamos cinco reuniões semanais das Secretarias Municipais de Turismo, Diretorias de Esporte e Cultura durante o ano de 2012. Nesse período também acompanhamos e observamos todas as reuniões mensais do Conselho Municipal de Turismo (COMTUR) e três do Conselho Municipal de Defesa do Meio Ambiente (COMDEMA) e fizemos o registro em diário de campo.

Ainda realizamos entrevistas com agentes importantes para o processo de implementação de tais políticas. Gestores e ex-gestores (gestões 2009-2012 e 2012-2012, no total de sete) e oito servidores das Secretarias de Esporte, Recreação e Cultura, Turismo, Meio Ambiente, Educação e Ação Social participaram dessa fase da pesquisa. Uma entrevista com o coordenador do Plano Diretor também foi realizada com o objetivo de aprofundarmos os aspectos técnicos e políticos dessa legislação. Foi realizada, ainda, entrevista com um dos ex-prefeitos, pois governou Brotas por três vezes e foi em um dos seus mandatos que ocorreram as principais mudanças administrativas na Prefeitura Municipal de Brotas. Um termo de consentimento livre e esclarecido foi assinado pelos entrevistados e a pesquisa autorizada pelo Comitê de Ética em Pesquisa.

A análise do conjunto de dados foi interpretativa e cotejamos os achados com a literatura existente sobre a temática. 


\section{APARATO LEGAL PARA O LAZER EM BROTAS}

No município de Brotas, os temas relacionados ao lazer estão presentes principalmente na Lei Orgânica Municipal e no Plano Diretor. No turismo há também leis específicas. A intersetorialidade aparece como sinônimo de integração de alguns programas e secretarias nas legislações estudadas.

Ao nos depararmos com o texto dessas legislações, num primeiro momento, avaliamos que havia um avanço considerável em relação ao que historicamente tem sido encontrado nas políticas públicas de lazer no Brasil. Pois, como denuncia Amaral (2011), essas políticas no país, historicamente, se apresentaram com caráter excludente, fragmentadas e funcionalistas. Outra característica que denota um descompasso com a inovação nominal que autores defendem para as políticas sociais é o fato de elas serem setoriais, planejadas e implementadas por um único departamento ou secretaria, com pouca ou nenhuma articulação com outros órgãos municipais. Menicucci (2006) e Bonalume (2010) defendem que o lazer, como conteúdo de uma política pública, devido às suas características multidisciplinares, deve ser formulado e executado por diversas secretarias para abranger toda a sua diversidade. As autoras ainda afirmam que uma das formas de se preencher essa lacuna é por meio da adoção da intersetorialidade.

Para Menicucci (2002, p.11), "[...] a intersetorialidade é uma nova forma de abordar os problemas sociais, enxergando o cidadão em sua totalidade e estabelecendo uma nova lógica para a gestão da cidade". Abreu (2009, p.111) conceitua a intersetorialidade como "[...] uma ação política e técnica de articulação entre setores visando à construção, reafirmação ou oposição a projetos coletivos que potencializam ou obstaculizam interesses coletivos". A intersetorialidade objetiva superar a forma segmentada e desarticulada como acontecem as ações públicas, "encapsuladas nos vários nichos setoriais ou disciplinares" (MENICUCCI, 2002, p. 11). Por meio de sua utilização, há um esforço de síntese de conhecimentos, de articular práticas para unificar o modo de produção de conhecimento e as estratégias de ação.

Com essa premissa analisamos a legislação sobre lazer em Brotas. A Lei Orgânica do município de Brotas (BROTAS, 1990) prevê, no seu Capítulo Il (Da competência do Município), Seção I, Artigo 10 (p. 3), que compete ao município "[...] prover a tudo quanto diga respeito ao seu peculiar interesse e ao bem-estar de sua população". Entre as atribuições, essa lei especifica os serviços ligados aos conteúdos esportivos, culturais e turísticos do lazer (p. 5): “[...] realizar programas de apoio às práticas desportivas [...]", proporcionar os meios de acesso "[...] à cultura, à educação e à ciência [...]" e "[...] promover o turismo como fator de desenvolvimento social e econômico".

Na Seção II (Dos Esportes e do Lazer), a Lei Orgânica prevê que é dever do município fomentar o esporte, como colocado no Artigo 153, (p. 50): o "[...] Poder Público valorizará o lazer como forma de integração social [...]", mediante o incentivo do lazer popular por meio de "[...] promoções, torneios estudantis, festivais de música, teatro, danças e festas de caráter regional" e, ainda, por meio da "[...] integração positiva do idoso à sua família e comunidade, favorecendo o funcionamento de entidades de lazer e amparo à velhice".

A Lei Orgânica também prevê, na Seção IV (Do Turismo), que a expansão do turismo na cidade tem como objetivos (p. 51): "I - Promover a divulgação dos aspectos ecológicos e dos pontos turísticos do município; II - Estabelecer contatos humanos e aproximar pessoas, através de viagens e excursões de lazer; III - Gerar divisas econômicas ao Município". Também 
está previsto que serão estabelecidos, em Lei Municipal, os critérios de sanções aos elementos depredadores do meio ambiente, de acordo com o estabelecido em Lei Federal. Ainda nessa seção, fica esclarecido que "[...] o Poder Público Municipal deverá preservar e manter em bom estado as áreas de belezas naturais, por serem estas locais de lazer e turismo".

No Artigo 158 (p. 51) dessa seção, fica estabelecido também que "o Poder Público dará especial atenção a todo tipo de esporte e lazer e entretenimento nos Centros Comunitários do Município".

Dessa forma, entende-se que o município de Brotas, por meio de sua Lei Orgânica, prevê a garantia do direito ao lazer, em consonância com a Constituição Federal, uma vez que confirma propostas de oferecimento de conteúdos do lazer (com ênfase no esporte, na cultura e no turismo) a todos os brotenses.

Para analisar o Plano Diretor de Brotas, enfatizamos o contexto de sua obrigatoriedade, a partir da Constituição de 1988, em que a questão da política urbana foi um dos destaques. A criação do Ministério das Cidades e do Conselho das Cidades estimulou o planejamento municipal e a gestão democrática das cidades. Um dos passos importantes foi a promulgação da lei 10.257, de 2001, conhecida como Estatuto da Cidade, um marco regulatório para que os municípios pudessem se instrumentalizar e materializar a vivência das funções sociais da cidade (trabalhar, habitar, circular e recrear), da propriedade urbana, o direito à cidade e à moradia. Assim, estabeleceu ser competência do poder público municipal a responsabilidade pela execução da política de desenvolvimento urbano e da gestão democrática.

Para que o Plano Diretor seja um instrumento da política de desenvolvimento e de expansão urbana e possa permitir sua viabilidade financeira, deve ser articulado com as peças orçamentárias, com o plano plurianual de investimentos, com a lei de diretrizes orçamentárias e com o orçamento anual (CARVALHO, 2001). Por ser um destino turístico, Brotas teve seu Plano Diretor formulado e publicado em 2006.

De acordo com Izzo Jr. (2007), essa legislação em Brotas foi realizada por um grupo amplo. Um entrevistado esclareceu que:

A intenção era fazer um plano verdadeiramente participativo, sem caráter ideológico ou político-partidário. Era lançar o ponto de vista para uma população que é desinformada e acostumada com o clientelismo. A proposta era levar outra imagem de como poderia ser a cidade. Como a escola é o local onde se concentra mais gente, então as crianças levavam os convites para os pais virem, foi o que surtiu efeito. Não foi uma participação como eu queria, mas não foi tão pequena assim. № recreio, a gente se reunia e eu levava o meu material de Brotas. Então o meu ideal era que essas pessoas que vieram de outra realidade, agora, teriam que abraçar essa realidade de Brotas, como se fosse o lugar delas. (ENTREVISTADO UM).

Apesar de essa fase do Plano Diretor ter previsto a participação efetiva da população, ela não aconteceu como imaginou a equipe técnica. Nas escolas, a linguagem utilizada pela equipe, a inibição dos moradores e a falta de um processo educativo que valorizasse a participação política, nas questões coletivas, dificultaram o processo. A saída encontrada pela equipe foi, então, utilizar um questionário. Foram solicitadas melhorias em muitas áreas. Em relação ao lazer, os pesquisados reivindicaram atividades culturais e esportivas para a cidade e as respostas expressaram capacidade de observação dos principais problemas urbanos e as questões sugeridas foram pertinentes. Houve, ainda, três audiências públicas na Câmara Municipal antes de sua aprovação. 
Antes de apresentar o Plano em suas questões técnicas, é indispensável mostrar as questões políticas encontradas na formulação do Plano Diretor do município. A principal atividade econômica de Brotas é a agroindústria canavieira. A área rural da cidade é extensa e as pressões dos empresários dessa área foram marcantes.

Eles estão pouco se importando para a cidade. O Plano Diretor é para organizar o crescimento urbano, ter os equipamentos de saúde, de educação. Nós somos um 'nada aqui', o resto é fazenda, é agronegócio. Eles não dependem da gente, nós dependemos deles: setenta por cento, por baixo, é renda do agronegócio. Mesmo quando tinha os interlocutores havia uma desconfiança muito grande (ENTREVISTADO UM).

A usina mais importante da cidade estava representada na Câmara Municipal, como foi relatado, e influenciou pontos do Plano Diretor:

\begin{abstract}
Houve uma tensão forte, já na própria Câmara. 0 presidente da Câmara dos Vereadores era um dos irmãos dos donos da propriedade Usina Paraíso. Ele falava pela Usina e não pela cidade. Nós tentamos fazer uma colocação do Plano Diretor, que ele avançasse nas áreas urbanizadas e mesmo nas áreas rurais do município. Elas não podem ser vistas como sendo dos coronéis dentro da fazenda, de porteira fechada, 'o que tá lá dentro é meu e ninguém põe a mão'. Mas foi o que prevaleceu. Ele trouxe o Estatuto da Cidade que dizia que o Plano Diretor envolve as questões do município nas áreas das áreas urbanizadas. Então, na área rural, isso não teria efeito. Foi vetado todos os artigos que intervinham na área rural (ENTREVISTADO UM).
\end{abstract}

Assim, o poder econômico influenciou a formulação do Plano Diretor de Brotas e demonstrou a importância desses atores nas políticas públicas na cidade. Outros atores, como loteadores, também tensionaram o Plano Diretor, mas a organização foi mantida.

No que se refere às questões técnicas, o Plano Diretor se destacou, uma vez que propôs sua articulação por meio de espaços públicos de lazer, dos parques da cidade, de forma que estes fossem agentes de urbanização para seu entorno. Nesse caso, "[...] assume-se para a cidade que se quer, um perfil ecológico, voltado para o equilíbrio entre cultura e natureza e para a criação de um habitat humano com qualidade real de vida" (IZZO JR., 2007, p. 268). De acordo com o autor, esse perfil implicou uma visão que respeitasse a identidade local, assim como a preservação das áreas de significado histórico e arquitetônico do município.

A adoção dessa articulação dos parques (da Cidade, do Viveiro Municipal, da Estação Ferroviária, dos Saltos e da Lagoa Dourada,) foi um elemento fundamental e inovador no Plano Diretor de Brotas e tinha como propósito "[...] tornar mais homogênea a ocupação da cidade, sem perda das características formadas em seu desenvolvimento histórico, acentuando a importância da vinculação do desenho urbano com o patrimônio ambiental" (IZZO JR., 2007, p. 270). A partir desses espaços, esse sistema municipal proposto objetivava transformar cada parque em um agente catalisador de transformação do seu entorno e foi planejado para acontecer num prazo de dez anos. Essa articulação iniciou-se com a revitalização do Parque dos Saltos, por estar localizado no centro da cidade e às margens do rio Jacaré-Pepira, símbolo da identidade local e um dos principais atrativos da cidade.

Izzo Jr. (2007) salienta que, por ser cidade turística, o Plano Diretor previa atransformação de Brotas em estância turística, nomeação ocorrida em 2014 e, com isso, o município receberá anualmente recursos financeiros do governo do estado. 
Ainda em relação aos conteúdos do lazer, o Plano Diretor prevê, em seu Capítulo VIII, Da Cultura, as diretrizes para a política cultural do município e considera que este deve levar em conta "[...] as características locais, buscando integrar suas atividades ao cotidiano da cidade (Fls. 17)".

Quanto ao turismo, potencial da cidade, o Plano Diretor previa a instalação de uma Secretaria Municipal de Turismo, que existe desde 2007, com o propósito de fortalecê-lo como atividade econômica. É nessa área que aparece a preocupação explícita com um os objetivos deste estudo, ou seja, a adoção da intersetorialidade na gestão da cidade:

[...] as atividades ligadas ao turismo deverão promover sua integração com os diversos órgãos municipais nas áreas de esporte, lazer, educação e cultura, de forma a implementar a oferta turística e a infraestrutura de apoio e promover 0 conhecimento histórico-cultural de Brotas (PLANO DIRETOR, 2006, f. 18).

No Capítulo X, Do Esporte, a prefeitura municipal se compromete a propiciar e a incentivar a prática esportiva para todos os segmentos da comunidade. $\mathrm{O}$ documento prevê a promoção de oportunidades aos cidadãos, o oferecimento de formas de aprendizagem e de desenvolvimento físico para a prática de esportes em todo o município. Para atingir esses objetivos, a prefeitura se propõe a recuperar, a manter, a ampliar e a criar espaços e equipamentos, bem como centros esportivos destinados ao esporte para toda a comunidade brotense (PLANO DIRETOR, 2006).

Fica evidente no documento o compromisso do poder público em atender os cidadãos em relação ao esporte: incentivar o investimento da iniciativa privada para programas que atenderão a iniciação esportiva para a criança, o adolescente, os amadores e os atletas que representem o município. Ainda deverá incentivar a organização e/ou a participação de competições esportivas e desenvolver programas para práticas esportivas para a terceira idade e portadores de deficiência.

Também está presente o compromisso da prefeitura em promover parcerias com organizações da sociedade para a promoção de programas esportivos e viagens de lazer. Encontramos também no Plano Diretor que na educação e no meio ambiente a gestão pública municipal deve ser de responsabilidade de vários setores e, ainda, de outras instituições privadas e privadas sem fins lucrativos.

É indispensável destacar que os conteúdos do lazer são contemplados na Lei Orgânica e no Plano Diretor, como garantias de direitos constitucionais e eixos para as políticas públicas. Pressupúnhamos que esse conjunto de leis poderia se desdobrar em inúmeras ações na área do lazer e indicariam um esforço de trabalho conjunto. Contudo, a análise das ações mostrou um descompasso quando se trata do lazer esportivo participativo e ambiental, e demonstrou um empenho no tocante ao lazer turístico de negócio.

\section{DESCOMPASSO ENTRE O LAZER ESPORTIVO PARTICIPATIVO E AMBIENTAL E 0 LAZER TURÍSTICO EM BROTAS}

Ao analisarmos as legislações para o lazer em Brotas, estas indicavam um equilíbrio entre o que aqui denominamos de lazer esportivo participativo e ambiental e o lazer turístico de negócios, que poderia e deveria gerar recursos e formação de pessoal para implementar políticas públicas voltadas ao cidadão brotense. Teoricamente, entendemos que o lazer 
esportivo participativo se materializa na forma de ações voltadas à promoção da democratização esportiva e da sustentabilidade ambiental. Deve acontecer, sobretudo, por meio de propostas educativas para os cidadãos e de acesso a diferentes espaços para todos. Ainda, incentivará a preservação do meio ambiente e o uso de espaços naturais com a menor interferência possível, enquanto o lazer turístico se materializa por meio de ações que visem garantir 0 desenvolvimento do turismo como fonte geradora de recursos financeiros em que os lucros são revertidos na forma de políticas públicas e turismo cidadão. Entendemos turismo cidadão na perspectiva de Gastal e Moesch (2007). Para nós, o turismo cidadão contrapõe a visão de turismo somente como atividade econômica e o inclui como direito ao lazer. Pressupõe políticas públicas cujos objetivos "[...] contribuam para a qualidade de vida da comunidade local, e em consequência, dos turistas. E que elas legitimem seu valor social ao se tornarem uma estratégia de defesa do meio ambiente e das manifestações culturais locais [...]" (GASTAL, MOESCH, 2007, p. 55).

No caso de Brotas, há na legislação clara indicação de que a geração de renda pelo turismo deveria ser revertida em políticas públicas para a cidade e seus moradores. Também pressupúnhamos que o esforço intersetorial estaria presente naquela gestão. Mas, como 0 título desta seção indica, identificamos um descompasso entre as duas ênfases dadas ao lazer. O lazer turístico de negócios tem sido o maior foco da prefeitura e, mais ainda, havia nessa administração a facilitação do turismo exploratório, no qual os negócios se dirigem aos interesses privados e privatistas.

Para analisarmos essas duas ênfases dadas ao lazer em Brotas, tomamos dois modelos de gestão que surgiram no Brasil no campo da administração pública: a gerencial e a societal (PAULA, 2005).

A administração gerencial se baseia no movimento gerencialista com uma dimensão econômico-financeira e institucional-administrativa, cujos objetivos são: melhorar as decisões estratégicas do governo e da burocracia; garantir a propriedade e o contrato; garantir a autonomia e a capacitação gerencial do administrador público; e assegurar a democracia por meio da prestação de serviços para o "cidadão cliente" (PAULA, 2005). O processo decisório é centralizador no que se refere à participação popular e é participativo somente no discurso. Traz uma abordagem de gestão que "[...] enfatiza a adaptação das recomendações gerencialistas para o setor público" (PAULA, 2005, p. 175).

A gestão pública societal enfatiza a participação social e procura estruturar um projeto político que repense o modelo de desenvolvimento brasileiro, a estrutura do aparelho de Estado e o paradigma de gestão. Trata-se de um modelo que valoriza as estruturas e canais que viabilizem a participação popular. Apresenta uma abordagem de gestão que "[...] enfatiza a elaboração de experiências de gestão focalizadas nas demandas do público-alvo, incluindo questões culturais e participativas" (PAULA, 2005, p. 175). Fica evidente que a gestão em Brotas durante o período analisado no tocante ao lazer tendeu a ser gerencial.

Vejamos o que sustenta nossos argumentos. Em relação ao lazer esportivo participativo identificamos algumas ações setorializadas, cuja continuidade não foi garantida. Na Diretoria de Cultura a maioria dos pontos indicados pelas leis não foram implementados, embora os "shows da praça" tenham sido reativados. Tais shows eram apresentações musicais mensais em diversos espaços públicos da cidade, principalmente nas praças, cujos artistas são iniciantes e moradores de Brotas. 
A Secretaria de Esportes oferecia programas de atividades físicas e esportivas diversificadas para diversas faixas etárias.

No que se refere aos espaços esportivos, Brotas contava com muitos e novos espaços construídos e ampliados, por exemplo, as quadras e piscina no bairro Patrimônio, o Ginásio de Esportes "Brotão" e o Centro Comunitário, como previa o art. 38 do Plano Diretor. Nesses espaços, programas de "escolinhas" eram oferecidos, porém com pouca integração entre as secretarias municipais.

Em relação ao artigo 39 do Plano Diretor, a prefeitura realizou convênios com 0 SESI da cidade para promover a iniciação esportiva de crianças e adolescentes. Também foi contemplada a participação dos moradores em competições. Brotas sedia competições em nível nacional, principalmente aquelas de aventura, como o Campeonato Nacional de Rafting. Embora essas competições contemplem categorias de moradores e os dispensem de pagar taxa de inscrição, os maiores beneficiados com esses eventos são os empresários do turismo.

No que se refere ao oferecimento de atividades esportivas para a terceira idade, o poder público não implementou os programas voltados aos portadores de deficiência, como previsto.

O repertório de ações de Brotas voltadas para o lazer esportivo ambiental apresentava um lugar comum, presente em diversas cidades brasileiras, em que a secretaria que historicamente é responsável pelo lazer oferece os esportes tradicionais, de forma departamentalizada e fragmentada. Chamou-nos a atenção o pouco aproveitamento do potencial natural da cidade em prol do cidadão. Havia em Brotas possibilidades de corrida de orientação, rafting, boiacross, rapel etc., contudo, tais atividades não compunham ações de lazer esportivo ambiental, com exceção da escolinha de rafting (que, pelas observações, acontecia numa lagoa poluída).

Além disso, notamos, em quase todas as ações apresentadas em Brotas, potencial de políticas intersetoriais, contudo, quando aconteciam, eram feitas em parcerias "frouxas", em que havia colaboração, mas não o compartilhamento de planejamento, ação e avaliação.

Já em relação ao lazer turístico de negócios, é possível concluir que a maioria dos pontos presentes nas leis haviam sido implementados. Contudo, como afirmamos, voltados para o lucro do setor privado e sem a preocupação em promover ações revertidas para políticas públicas para o cidadão.

No que se refere à integração do turismo com a população, esta se dá por meio da aplicação da lei do "Dia do Turismo". A Lei Municipal 2400/2010 institui este dia e "[...] suas comemorações terão caráter educativo, informativo, social e de lazer" (f.1). Nesse dia, as agências sorteiam ingressos aos alunos da rede escolar para que tenham a oportunidade de conhecer os atrativos e vivenciar o lazer. A Lei também obriga todas as secretarias da prefeitura a colaborarem na sua aplicação e, ainda, autoriza a Secretaria de Turismo a firmar parcerias com associações, ONGs, entidades e com o segmento privado do turismo no município com o objetivo de promover a integração da comunidade com o meio turístico. Ora, tais ações, a nosso ver, resultam em fortalecimento e favorecimento das empresas operadoras do turismo em Brotas e são pouco efetivas numa educação ambiental e não garantirão a preservação dos espaços naturais de lazer do município.

Há sim, por parte da prefeitura, esforços quanto à melhoria da qualidade dos serviços turísticos e à profissionalização deles, como previsto no Plano Diretor. Uma das formas de se viabilizar isso se dá por meio de cursos oferecidos aos guias e condutores, o anual Seminário 
Técnico de Condutores de Turismo de Aventura. Mais uma vez essa ação denota 0 caráter privatista do lazer turístico de negócios.

Alguns pontos do Plano Diretor que tenderiam ao lazer ambiental e participativo não foram alcançados. Não foram elaborados roteiros turísticos de visitação das principais culturas agrícolas da cidade, a cana-de-açúcar, a laranja e o eucalipto. Tais roteiros poderiam valorizar as características do município e ser revertidos em políticas públicas para o cidadão brotense, já que implementariam ganhos ao pequeno produtor, que vive e conhece o dia a dia dos espaços naturais de Brotas.

Outro ponto do Plano Diretor que não foi implementado na área do turismo é o que se refere às leis que tratam da preservação ambiental do município. Desde 2002, Brotas tem uma Política Municipal de Desenvolvimento do Turismo Sustentável (PMTS). A partir dessa lei, outras foram criadas com essa finalidade. São 13 leis que regulamentam a ação das agências de turismo, dos meios de hospedagem e dos sítios turísticos, bem como todas as práticas corporais oferecidas na natureza, como o rafting, o boiacross, etc. Essa normatização é imprescindível para a sustentabilidade ambiental, a qualidade dos serviços oferecidos e segurança dos participantes. Dessas legislações, podemos destacar aqui três: a Lei número 1.874/2003, a número 1.927/2003 e a número 1.930/2003. A primeira dispõe sobre a necessidade e a obrigatoriedade do Licenciamento Turístico Ambiental no município, denominado LTA. Tem o objetivo (BROTAS, 2003, f. 1) de "[...] diminuir o impacto causado pelo Turismo por meio do estabelecimento de condições, restrições e medidas de controle ambiental."

Trata-se de um

[...] procedimento administrativo pelo qual o poder público municipal, através de seus organismos competentes, licencia a localização, instalação, ampliação e a operação de empreendimentos e atividades turísticas utilizadoras dos recursos ambientais, consideradas efetiva ou potencialmente poluidoras ou degradadoras do ambiente, nos termos das disposições legais e regulamentares e das normas técnicas aplicáveis ao caso (BROTAS, 2003, f. 1).

A segunda (BROTAS, 2003, f. 1) diz respeito à ação dos condutores de turismo no município. Dispõe sobre suas "[...] responsabilidades e deveres, normatiza os equipamentos necessários, estabelece um código ético de conduta e condições mínimas para o exercício do cargo". Reforça a necessidade da promoção de "[...] ações de educação e conservação ambiental [...]", durante as práticas turísticas do município.

E a terceira (BROTAS, 2003, Fls. 1) cria o Serviço Municipal para o Turismo Sustentável (SMTS) e, neste, o Sistema de Controle de Visitação Turística cujo propósito "[...] é controlar, através da emissão de um ingresso ou voucher ${ }^{2}$, a visitação turística nos atrativos naturais". Entretanto, nenhuma dessas três legislações tem sido implementada pelo poder público, e os impactos ambientais negativos já se apresentam no município, como mostrou Silva (2006).

Em relação à Licença Turística Ambiental (LITA), somente três empreendimentos na cidade a possuem. Nas observações nas reuniões do Comtur, ouvimos reclamações quanto ao descaso da prefeitura em cobrar dos outros empresários esta licença.

2 No turismo, voucher corresponde a um "documento emitido por uma agência de turismo que comprova junto ao prestador de serviço determinada reserva e o seu pagamento" (BOITEUX; WERNER, 2009, p. 149). Com sua emissão, é possível controlar o fluxo de turistas em atrativos turísticos naturais. 
No Comtur, participantes também se manifestaram contra a pouca fiscalização no turismo e sobre os impactos ambientais percebidos. Isso poderia ser solucionado com a aplicação da terceira lei (BROTAS, 2003, f. 2), a do voucher ou ingresso, pois estes garantiriam "[...] a sustentabilidade turística e ambiental dos serviços e produtos existentes no município [...]", como acontece, com sucesso, por exemplo, na cidade de Bonito, $\mathrm{MS}^{3}$, destino em que o setor público de Brotas se baseou para formular essa lei.

Os empresários participantes do Comtur, por sua vez, fazem o discurso da sustentabilidade, mas não se preocupam com o número de turistas permitidos nos atrativos naturais. Observações realizadas em um feriado na cidade, assim como a pesquisa de Silva (2006), comprovaram esse descaso.

A PMTS foi aprovada na gestão de um dos entrevistados desta pesquisa e questionamos o motivo da não implantação da lei do voucher.

[...] o voucher não foi implantado, pelo mesmo motivo. Brotas tinha 16 agências e alguém queria montar mais uma. Isso quando o turismo passava por uma baixa. Em 2007, o momento econômico era satisfatório, mas as empresas não estavam preparadas. Uma parte se profissionalizou, outra não. Com a implantação do voucher, naquele ano, aquilo 'mataria' muitas empresas e essa é a questão (...). Em 2008, era ano político, era inviável. Esse é o motivo real com relação ao voucher. Esse foi o motivo (ENTREVISTADO QUATRO).

Assim, a Normatização Turística foi aprovada há mais de dez anos e somente algumas de suas leis foram implementadas. Aplicar essas leis resultará em negociações e tensões de todos os setores e demonstra o caráter político do Plano Diretor e outras legislações (CARVALHO, 2001). Mas, ao que parece, a vontade política da gestão municipal caminha lado a lado a uma gestão empresarial da política, na qual o lazer turístico de negócio privatiza o que um dia foi dos cidadãos de Brotas e que deveria ser preservado como patrimônio para futuras gerações.

Luchiari (2000) alerta que todo planejamento do espaço turístico deve ter como referência a realidade do lugar, que "[...] o planejamento turístico deveria ser um planejamento do lugar, da vida daqueles que ficam e permanecem em suas trajetórias cotidianas" (LUCHIARI, 2000, p. 41). A autora afirma que 0 desenvolvimento de determinadas metodologias específicas para 0 planejamento dos espaços turísticos deve ser prudente com o exacerbado otimismo econômico que, ao defender os benefícios em curto prazo, perde de vista os custos socioambientais a médio e longo prazo.

Brotas apresenta uma legislação avançada nessa área, foi pioneira e modelo na época de sua formulação, mas não aplicava a maioria das leis da PMTS. É importante destacar isto, já que as consequências trarão maior impacto ao cidadão e não para o turista. O rio Jacaré-Pepira é um símbolo de identidade local onde muitos brotenses vivenciam o seu lazer, e sua preservação é fundamental para todos. Esse é um exemplo dos atrativos naturais que têm sofrido impactos negativos do turismo (SILVA, 2006). Agnelli (2006) analisou que a não aplicação dessas leis e a falta de planejamento está levando Brotas ao declínio como um destino turístico. 


\section{CONSIDERAÇÕES FINAIS}

Como anunciamos no início, nosso objetivo foi de estudar a intersetorialidade nas políticas públicas de lazer em Brotas, especialmente porque nesse município foram criadas legislações ligadas ao lazer consideradas inovadoras. Deparamo-nos com passagens na Lei Orgânica e do Plano Diretor de Brotas com aspectos ligados à inovação na gestão do lazer com tendências intersetoriais.

As legislações em Brotas indicavam um equilíbrio entre o lazer esportivo participativo e ambiental e o lazer turístico, no qual o segundo poderia e deveria gerar recursos e formação de pessoal para implementar políticas públicas voltadas ao cidadão brotense. Havia, na legislação, clara indicação de que a geração de renda pelo turismo deveria ser revertida em políticas públicas para a cidade e seus moradores. Pressupúnhamos que o esforço intersetorial estaria presente no cotidiano daquela gestão, mas identificamos um descompasso entre as duas ênfases dadas ao lazer. O lazer turístico de negócios foi o maior foco da prefeitura, que facilitava o turismo exploratório em que os negócios se direcionavam aos interesses privados e privatistas.

Brotas apresentou uma legislação considerada avançada na área, mas não aplicou a maioria das leis da PMTS. É importante destacar isto, já que as consequências trarão maior impacto ao cidadão do que ao turista, com várias consequências para as políticas públicas de lazer.

\section{REFERÊNCIAS}

ABREU, Cassiane Caminoti. A intersetorialidade no processo de construção da política de saúde brasileira. 184 f. 2009. Dissertação (Mestrado em Política Social) - Centro de Ciências Jurídicas e Econômicas, UFES, Vitória, 2009.

AGNELLI, Selma Aparecida Cury. A Implementação da atividade turística em Brotas - SP: euforia e declínio. 150 f. 2006. Dissertação (Mestrado em Desenvolvimento Regional e Meio Ambiente) - Centro Universitário de Araraquara, UNIARA, Araraquara, 2006.

AMARAL, Sílvia Cristina Franco. Lazer: temática transversal e intersetorialidade. 194 f. 2011. Tese de Livre Docência - Faculdade de Educação Física. Universidade Estadual de Campinas, Campinas, 2011.

BOITEUX, Bayard; WERNER, Maurício. Introdução ao estudo do turismo. Rio de Janeiro: Elsevier, 2009. BONALUME, Claúdia Regina. 0 Esporte e o lazer na formulação de uma política pública intersetorial para a juventude: a experiência do PRONASCl. 215 f. 2010. Dissertação (Mestrado em Educação Física) Faculdade de Educação Física, UNB, 2010.

BRASIL. Câmara dos Deputados. Lei Federal n. 10257 (Estatuto da cidade): regulamenta os artigos 182 e 183 da Constituição Federal, estabelece diretrizes gerais da política urbana. Disponível em: <http://www.planalto. gov.br/ccivil 03/leis/LEIS 2001/L10257.htm> Brasília, 2002. Acesso em: 23 out. 2014.

BROTAS. Prefeitura Municipal. Lei Orgânica Municipal. Brotas, 1990.

BROTAS. Prefeitura Municipal. Lei municipal 1.846/2002: Dispõe sobre a Política Municipal de Turismo Sustentável (PMTS) e o funcionamento das atividades e empreendimentos turísticos o município. Brotas, 2002. Disponível em: <www.brotas.sp.gov.br.> Acesso em: 3 mar. 2012.

BROTAS. Prefeitura Municipal. Lei municipal 1.874/2003: Dispõe sobre o Licenciamento Turístico Ambiental (LTA). Brotas, 2003. Disponível em: <www.brotas.sp.gov.br.> Acesso em: 3 mar. 2012. 
BROTAS. Prefeitura Municipal. Lei municipal 1930/2003: Dispõe sobre a criação o Sistema Municipal de Controle da Visitação Turística (SMCV). Brotas: 2003. Disponível em: <www.brotas.sp.gov.br.> Acesso em: 3 mar. 2012.

BROTAS. Prefeitura Municipal. Lei complementar n. 0012/2006: institui o Plano Diretor do município. Brotas, 2006. Disponível em: <http://www.brotas.sp.gov.br/administracao/arquivos leis/plano diretor.pdf.> Acesso em 3 mar.2012.

CARVALHO, Sônia Nahas. Estatuto da cidade: aspectos políticos e técnicos do plano diretor. São Paulo em perspectiva, São Paulo, v. 15, n. 4, p. 130-135, 2001.

GASTAL, Susana; MOESCH, Marutschka Martini. Turismo, políticas públicas e cidadania. São Paulo: Aleph, 2007.

IZZO JR., Alcino. Brotas: por um turismo consciente. OLAM, Rio Claro, v.7, n. 1, p. 260-278, 2007.

LUCHIARI, Maria Tereza D. P. Turismo e meio ambiente na mitificação dos lugares. Turismo em análise. São Paulo, v.11. n. 1, p. 33-43, maio 2000.

MENICUCCI, Telma Maria Gonçalves. Intersetorialidade, o desafio atual para as políticas sociais. Pensar BH/ Política social, Belo Horizonte, Edição Temática, n. 3. p. 10-13, maio/jul.2002.

MENICUCCI, Telma Maria Gonçalves. Políticas públicas de lazer: questões analíticas e desafios políticos. In: LINHALES, Meily; ISAYAMA, Helder Ferreira. (Orgs.). Sobre lazer e política: maneiras de ver, maneiras de fazer. Belo Horizonte: Editora UFMG, 2006. p.136-164.

MINAYO, Maria Cecília de Souza; DESLANDES, Suely Ferreira; GOMES, Romeu. Pesquisa social: teoria, método e criatividade. Petrópolis: Vozes, 2009.

PAULA, Ana Paula Paes. Por uma nova gestão pública: limites e potencialidades da experiência contemporânea. Rio de Janeiro: Editora FGV, 2005.

SILVA, Charlei Aparecido. Análise sistêmica, turismo de natureza e planejamento ambiental de Brotas: proposta metodológica. 270 f. 2006. Tese (Doutorado em Geografia) - Instituto de Geociências, Universidade Estadual de Campinas, 2006. 